\title{
CRESCIMENTO INICIAL DE MUDAS DE Acacia mangium CULTIVADAS EM MANTAS DE FIBRA DE COCO CONTENDO SUBSTRATO DE LODO DE ESGOTO ${ }^{1}$
}

\author{
Rômulo Fredson Duarte², Regynaldo Arruda Sampaio ${ }^{3}$, Delacyr da Silva Brandão Junior ${ }^{3}$, Humberto \\ Pereira da Silva ${ }^{4}$, Nathália de Souza Parreiras ${ }^{3}$ e José Maria Gomes Neves ${ }^{5}$
}

\begin{abstract}
RESUMO - O objetivo deste trabalho foi avaliar o crescimento inicial de mudas de Acacia mangium semeadas em "manta" de fibra de coco contendo substrato de lodo de esgoto. O delineamento experimental foi em blocos casualizados com 13 tratamentos e três repetições, distribuídos em esquema fatorial $(6 \times 2+1)$ com seis proporções de fibra de coco e resíduo agregante, combinados com substratos com e sem lodo de esgoto, mais o tratamentocontrole (terra de subsolo). Foram avaliados o índice de velocidade de emergência (IVE), a percentagem de emergência (EM) e a altura das plantas aos 40 e 60 dias após a emergência. O tratamento- controle apresentou melhores resultados em relação ao IVE e EM quando comparado com os tratamentos utilizando "manta" de fibra de coco e resíduo agregante. Não houve diferença entre o controle e os tratamentos com "mantas" em altura das plantas aos 40 e 60 dias. Não foram observadas interações entre o tipo de substrato utilizado no semeio e as diferentes proporções de fibra de coco na "manta". A presença de lodo no substrato não influenciou o IVE e a EM, contudo verificou-se que o substrato sem lodo de esgoto proporcionou maior crescimento em altura das plantas. O uso de "mantas" contendo 50 e 100\% de fibra de coco proporcionou maior crescimento às mudas de acácia em condições de campo.
\end{abstract}

Palavras-chave: Biossólido, Germinação e Resíduos.

\section{INITIAL GROWTH OF Acacia mangium GROW CULTIVATED IN COCONUT FIBER BLANKET WITH SUBSTRATUM OF SE WAGE SLUDGE}

\begin{abstract}
The objective of this work was to study the initial growth of Acacia mangium in coconut fiber "blanket" with a substrate of sewage sludge. The experimental design was of a randomized block with 13 treatments, three repetitions, in a factorial project $(6 \times 2+1)$, with 6 ratio of coconut fiber and aggregating residue, combined with presence and absence of sewage sludge, and treatment control (subsoil land). The speed emergency index (IVE), percentage of emergency (EM) and plant height at the 40 and 60 days after emergency was evaluate. No interaction was observed between the type of substrate used and the different ratio of coconut fiber in the "blanket". The presence of sewage sludge in the substrate did not influence the IVE and EM, however it was verified that the substrate without sewer silt provided greater growth in plant height. The use of "blankets" with 50 and 100\% coconut fiber provided greater growth of the A. mangium grow in field conditions.
\end{abstract}

Keywords: Sewage Sludge, Germination and Residues.

\footnotetext{
${ }^{1}$ Recebido em 12.05.2008 e aceito para publicação em 25.08.2010.

${ }^{2}$ Mestre em Ciências Agrárias/Agroecologia pela Universidade Federal de Minas Gerais, UFMG, Brasil. E-mail: <agroromulo@yahoo.com.br>.

${ }^{3}$ Universidade Federal de Minas Gerais, UFMG, Brasil. E-mail: <rsampaio@ufmg.br>, <dsbrandaojr@ufmg.br> e $<$ nathaliaparreiras@ig.com.br>.

${ }^{4}$ Universidade Federal de Lavras, UFLA, Brasil. E-mail: <humbertofu@yahoo.com.br >.

${ }^{5}$ Universidade Federal de Viçosa, UFV, Brasil. E-mail: <josemariauf@yahoo.com.br>.
} 


\section{INTRODUÇÃO}

Atualmente há intensa busca dos órgãos ambientais, instituições de pesquisa e diversos segmentos da sociedade por formas alternativas e ecologicamente corretas para evitar impactos negativos no ambiente pelas ações antrópicas. Esses esforços se concentram no estudo de espécies nativas (FARIA et al., 1997; FERREIRA et al., 2007), semeadura direta com espécies arbóreas (ARAKI, 2005) e aplicação de adubos orgânicos (KITAMURA et al., 2008; CAMPOS e ALVES, 2008). Essas são algumas das medidas investigatórias para conter a degradação dos solos e recuperar áreas degradadas.

A qualidade das mudas é fator fundamental para o sucesso de povoamentos florestais (NEVES et al., 2005), sendo, com isso, possível produzir mudas em grande quantidade e com qualidade.

Entre as leguminosas arbóreas, a Acacia mangium Willd destaca-se pela rusticidade e adaptabilidade às condições adversas de solo e clima, pelo rápido crescimento, elevada produção de biomassa e capacidade de formar simbioses com microrganismos do solo (COLONNA et al., 1991). De ocorrência natural na Nova Guiné, Indonésia e algumas regiões da Austrália, essa espécie apresenta grande potencial de uso em programas de reflorestamento e recuperação de áreas com solos pobres ou degradados, como as áreas de encostas e de mineração, além de possibilitar a produção de madeira, celulose, carvão e outros produtos (EMBRAPA, 1992).

A fibra da casca do coco pode ser importante na produção de substratos de boa qualidade para a produção de mudas ou em cultivos sem o uso do solo (CARRIJO et al., 2002). Substrato como o pó de coco é leve, de fácil manuseio, com boa capacidade de absorção de água, não exige o reumedecimento diário e proporciona bom desempenho germinativo das sementes (SOUZA et al., 2007). Carrijo et al. (2004), por meio da comparação da fibra de coco com outros tipos de substratos, mostraram leve superioridade da fibra de coco na produção comercial de tomate, produzindo aproximadamente uma tonelada a mais de frutos comerciais que o pó de serra ou serragem em três anos de avaliação.

A utilização de lodo de esgoto na agricultura traz o benefício da reciclagem da matéria orgânica e de nutrientes, em especial o nitrogênio, pelo seu valor econômico (BOEIRA, 2006). Santos et al. (1999), trabalhando com composto orgânico de lixo urbano na cultura da alface, verificaram acréscimo no conteúdo de matéria orgânica do solo. Quando aplicado ao solo, o adubo orgânico aumenta a capacidade de troca de cátions (CTC), os teores de nutrientes, a retenção de água, a porosidade e a aeração, além de reduzir o encrostamento e selamento superficial do solo. Em países industrializados, o lodo de esgoto é usado como fertilizante alternativo há muito tempo; por esse motivo, foram realizadas muitas pesquisas sobre os efeitos no solo desse resíduo. Entretanto, os resultados, que foram obtidos em solos de clima temperado, dificilmente podem ser extrapolados para solos ácidos e de clima tropical (SILVA et al., 2001).

Ações que visam à recuperação de áreas degradadas, por meio da produção de mudas arbóreas de qualidade, bem como o estudo de alternativas de intervenção técnica para acelerar o processo de recomposição vegetal em curto prazo, tornam-se imprescindíveis. No Brasil há poucos estudos sobre a A. mangium Willd, como os de Daniel et al. (1997), que analisaram efeitos de fósforo em mudas com 80 dias de idade; e de Silva et al. (1996), que estudaram procedências de materiais genéticos da mesma espécie.

Visando auxiliar no processo de recuperação de áreas degradadas, este trabalho tem como objetivo avaliar o crescimento inicial de mudas de Acacia mangium Willd semeadas em "manta” de fibra de coco contendo substrato de lodo de esgoto.

\section{MATERIAL E MÉTODOS}

O experimento foi conduzido nos meses de outubro a dezembro de 2007, no Laboratório de Análise de Sementes do Instituto de Ciências Agrárias (LAS/ICAUFMG) e, posteriormente, em uma área do Campus da UFMG, em Montes Claros, MG.

O delineamento experimental utilizado foi o de blocos casualizados com 13 tratamentos e três repetições, distribuídos em esquema fatorial $(6 \times 2+1)$ com seis proporções de fibra de coco/resíduo agregante (100\% е $0 \%, 90 \%$ е $10 \%$, $80 \%$ е $20 \%$, $70 \%$ е $30 \%$, $60 \%$ е $40 \%$ e $50 \%$ e $50 \%$ ), com lodo (terra de subsolo de Latossolo Vermelho Amarelo + lodo de esgoto na proporção 2:1) e sem lodo de esgoto (terra de subsolo + esterco bovino 
curtido na relação 3:1) mais o tratamento-controle (terra de subsolo). Os substratos foram colocados na superfície das “mantas", formando uma camada, para que fosse efetuado o plantio das sementes de A. mangium Willd. O lodo de esgoto foi oriundo da Estação de Tratamento de Esgoto (ETE) localizada na cidade de Juramento, próximo a Montes Claros, MG.

As fibras de coco utilizadas no trabalho foram extraídas de cascas de frutos utilizados por pequenas fábricas do mercado local para obter a "água de coco". A coleta da casca ocorreu nos próprios locais de venda de água de coco, descartando-se aquelas de coloração marrom, porque apresentavam maior dificuldade para serem processadas. Os cocos verdes foram deixados em ambiente natural com a temperatura em torno de $25^{\circ} \mathrm{C}$ até atingirem aproximadamente $20 \%$ de umidade, de forma a favorecer a moagem (ROSA et al., 2001).

A fibra foi obtida em máquinas desintegradora/ trituradora de forragem. As características químicas e físicas da fibra de coco utilizada para a fabricação da "manta” foram as seguintes: matéria orgânica $=24,8 \mathrm{~g} / \mathrm{dm}^{3}$; $\mathrm{pH}=6,6 ; \mathrm{N}=0,56 \mathrm{dag} / \mathrm{kg} ; \mathrm{P}=0,15 \mathrm{dag} / \mathrm{kg}$; $\mathrm{K}=1,15 \mathrm{dag} / \mathrm{kg} ; \mathrm{Ca}=0,45 \mathrm{dag} / \mathrm{kg} ; \mathrm{Mg}=0,20 \mathrm{dag} / \mathrm{kg}$; $\mathrm{S}=0,02 \mathrm{dag} / \mathrm{kg} ; \mathrm{Zn}=12 \mathrm{mg} / \mathrm{kg} ; \mathrm{Cu}=0,3 \mathrm{mg} / \mathrm{kg}$; $\mathrm{Mn}=14 \mathrm{mg} / \mathrm{kg}$; densidade $=0,98 \mathrm{~kg}$. $\mathrm{dm}^{-3}$; capacidade

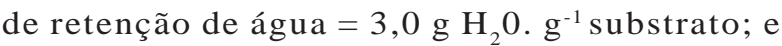
C.E. $=2,18 \mathrm{mS} / \mathrm{cm}(1: 5)$.

As “mantas” com dimensões de 34 x 24 x 5 cm foram colocadas na superfície do solo, dispostas no espaçamento de 1,0 x 0,5 m. Para evitar a perda de substrato das "mantas" pela irrigação ou pela chuva e, ainda, manter a sua umidade, foi colocado em sua superfície uma folha de jornal contendo 25 perfurações, onde foram plantadas 25 sementes de A. mangium Willd. O plantio ocorreu a aproximadamente $2 \mathrm{~cm}$ de profundidade, mas, antes disso, elas sofreram tratamento pré-germinativo para quebra de dormência, consistindo na imersão em água fervente $\left(100^{\circ} \mathrm{C}\right)$, por 60 seg, conforme Smiderle et al. (2005), irrigadas sempre que necessário.
No campo foram avaliadas as seguintes variáveis: índice de velocidade de emergência (IVE), percentagem de emergência (EM) e altura das mudas aos 40 e 60 dias após a emergência. Os dados em porcentagem (x) foram transformados em arcosseno de $(x / 100)^{0,5}$.

A média do tratamento adicional com as demais médias dos tratamentos foi comparada por contraste ortogonal e teste $\mathrm{F}$, enquanto as médias referentes às diferentes proporções de fibra de coco foram ajustadas a modelos de regressão com teste dos coeficientes até $10 \%$ de probabilidade pelo teste t.

Antes das avaliações de campo, as sementes foram submetidas à análise de umidade, massa de 1.000 sementes (BRASIL, 1992) e teste de germinação, em câmara de germinação a $25{ }^{\circ} \mathrm{C}$, no interior de caixas plásticas, em substrato papel germitest umedecido com 2,5 vezes seu peso de matéria seco com água destilada. As contagens foram feitas diariamente, considerando-se germinadas as sementes que apresentavam exposição da radícula. De posse do número de sementes germinadas diariamente, avaliaram-se as seguintes características: índice de velocidade de germinação (IVG), determinado de acordo com a fórmula apresentada por Maguire (1962) e germinação consideram-se, ao final do teste (18 dias), as plântulas normais que apresentavam as estruturas essenciais perfeitas (BRASIL, 1992).

\section{RESULTADOS}

O índice de velocidade de germinação (IVG) de A. mangium foi de $3,8 \%$, a germinação conseguiu atingir valores de até $87 \%$, juntamente com 5,1\% de umidade e 14,8 g referentes à massa de 1.000 sementes (Tabela 1).

Observa-se, na Tabela 2, que o tratamento-controle apresentou melhores resultados em relação ao índice de velocidade de emergência e percentagem de emergência de plantas, em comparação com os tratamentos utilizando "manta" de fibra de coco e resíduo agregante. Para a altura da planta aos 40 e 60 dias, entretanto, não houve diferença entre tratamentos (Tabela 2).

Tabela 1 - Características físicas e fisiológicas de sementes de A. mangium. Table 1 - Physical and physiological characteristics of the A. mangium seeds.

\begin{tabular}{ccccc}
\hline Espécie & IVG (\%) & Germinação (\%) & Umidade (\%) & Massa de 1.000 sementes (g) \\
\hline A. Mangium Willd & 3,8 & 87 & 5,1 & 14,8 \\
CV (\%) & 15,1 & 13,2 & 18,2 & 1,5 \\
\hline
\end{tabular}


Fonte: DUARTE, 2008.

Source: DUARTE, 2008.

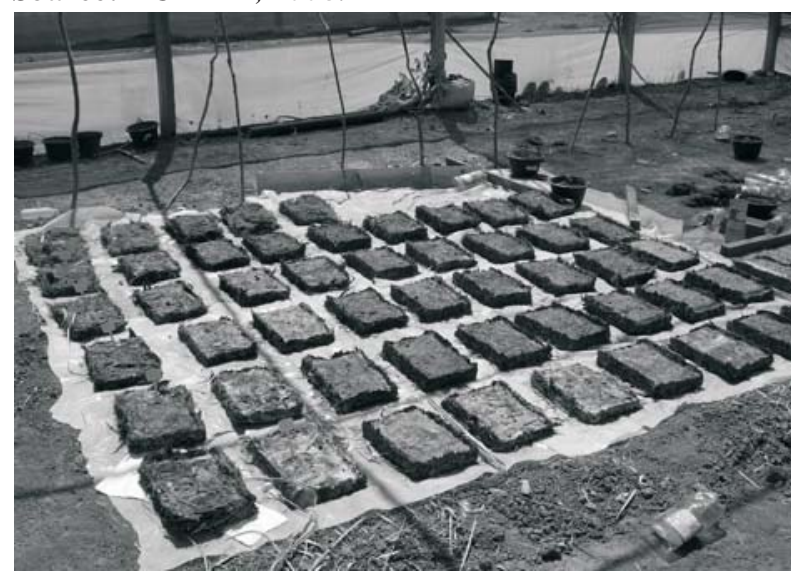

Figura 1 - A “manta” confeccionada.

Figure 1 - The confectioned "blanket".
Nos dados observados referentes a IVE e EM, não foram observadas interações entre o tipo de substrato utilizado no semeio e as diferentes proporções de fibra de coco na "manta" (Tabela 3). Foi observada que a presença de lodo no substrato não influenciou no índice de velocidade de emergência e, também, na percentagem de emergência das plantas (Tabela 3). Dados de altura das plantas medidas aos 40 (A40) e aos 60 (A60) dias após a emergência foram estatisticamente superiores em tratamentos em que foi utilizado o substrato sem o lodo de esgoto (Tabela 3).

Na Figura 2, mostra-se que, inicialmente, há maiores valores de índice de velocidade de emergência (IVE) e percentagem de emergência (EM) obtida na proporção de $50 \%$ de fibra de coco e, posteriormente, ligeiro decréscimo tanto no IVE quanto no EM de plantas de A. mangium, em função da proporção de fibra de

Tabela 2 - Contrastes ortogonais comparando tratamento-controle com tratamentos com "manta” de fibra de coco.

Table 2 - Ortogonais contrasts comparing the treatment control with the treatments with coconut fiber "blanket".

\begin{tabular}{lcccc}
\hline Contraste & IVE & $\mathrm{EM}^{1}$ & $\mathrm{~A} 40(\mathrm{~cm})$ & $\mathrm{A} 60(\mathrm{~cm})$ \\
\hline Controle x "Mantas" & $-0,25^{* *}$ & $-0,108^{* *}$ & $-0,59^{\mathrm{ns}}$ & $-6,39^{\mathrm{ns}}$ \\
\hline
\end{tabular}

${ }^{1}$ Médias transformadas para arcosseno $(\mathrm{x} / 100)^{0,5}$.

A40 e A60, altura da planta aos 40 e 60 dias da germinação, respectivamente.

ns e $^{* *}$ não significativo e significativo a $1 \%$ de probabilidade, respectivamente, pelo teste $\mathrm{F}$.

Tabela 3 - Índice de velocidade de Emergência (IVE), percentagem de emergência (EM), altura da planta (cm) medida aos 40 (A40) e 60 (A60) dias após a germinação das sementes de A. mangium em função da presença de lodo de esgoto no substrato e da proporção de fibras de coco (FC) e resíduo agregante (RA) na "manta".

Table 3 - Speed emergency index (IVE), percentage of emergency (EM), plant heigth at 40 (A40) and the 60 (A60) days after the germination of the seeds of A. mangium in function of sewage sludge in the substratum and of the proportion of coconut fiber (FC) and aggregating residue (RA) in the "blanket"

\begin{tabular}{|c|c|c|c|c|c|c|c|c|}
\hline & & \multicolumn{7}{|c|}{ Tratamentos } \\
\hline & & $\begin{array}{c}100 \% \mathrm{FC}+ \\
0 \% \mathrm{RA}\end{array}$ & $\begin{array}{c}90 \% \mathrm{FC}+ \\
10 \% \mathrm{RA}\end{array}$ & $\begin{array}{c}80 \% \mathrm{FC}+ \\
20 \% \mathrm{RA}\end{array}$ & $\begin{array}{c}70 \% \mathrm{FC}+ \\
30 \% \mathrm{RA}\end{array}$ & $\begin{array}{c}60 \% \mathrm{FC}+ \\
40 \% \mathrm{RA}\end{array}$ & $\begin{array}{c}50 \% \text { FC + } \\
50 \% \text { RA }\end{array}$ & Média \\
\hline \multirow[t]{3}{*}{ IVE } & S/lodo & 0,25 & 0,14 & 0,13 & 0,13 & 0,20 & 0,25 & 0,18 a \\
\hline & C/lodo & 0,30 & 0,21 & 0,15 & 0,29 & 0,25 & 0,33 & 0,26 a \\
\hline & Média & 0,28 & 0,18 & 0,14 & 0,21 & 0,23 & 0,29 & - \\
\hline \multirow[t]{3}{*}{$\mathrm{EM}^{1}$} & S/lodo & 0,051 & 0,006 & 0,012 & 0,010 & 0,023 & 0,059 & $0,027 \mathrm{a}$ \\
\hline & C/lodo & 0,067 & 0,029 & 0,019 & 0,076 & 0,029 & 0,074 & 0,049 a \\
\hline & Média & 0,059 & 0,018 & 0,016 & 0,043 & 0,026 & 0,067 & - \\
\hline \multirow[t]{3}{*}{ A $40(\mathrm{~cm})$} & S/lodo & 9,90 & 4,53 & 2,87 & 3,73 & 7,03 & 5,47 & 5,59 a \\
\hline & C/lodo & 8,27 & 5,10 & 4,37 & 3,57 & 5,00 & 3,50 & $4,97 \quad b$ \\
\hline & Média & 9,09 & 4,82 & 3,62 & 3,65 & 6,02 & 4,49 & - \\
\hline \multirow[t]{3}{*}{ A60 (cm) } & S/lodo & 23,80 & 10,30 & 6,80 & 3,73 & 16,63 & 12,97 & 13,25 a \\
\hline & C/lodo & 19,70 & 12,30 & 7,90 & 3,57 & 10,33 & 4,60 & $10,22 \mathrm{~b}$ \\
\hline & Média & 21,75 & 11,30 & 7,35 & 3,65 & 13,48 & 8,79 & \\
\hline
\end{tabular}

${ }^{1}$ Médias transformadas para arcosseno $(\mathrm{x} / 100)^{0,5}$.

Médias seguidas da mesma letra minúscula na vertical não diferem entre si, a 5\% de probabilidade, pelo teste F.

Revista Árvore, Viçosa-MG, v.35, n.1, p.69-76, 2011 
coco (FC). A partir daí, à medida que aumentou a proporção de FC nas “mantas” houve aumento dos valores referentes a IVE e EM, proporcionando melhores características de crescimento às mudas de acácia em condições de campo.
O uso de "mantas" contendo 50 e $100 \%$ de fibra de coco, 50\% FC + 50\% RA e 100\% FC + 0\% RA, respectivamente, representou acréscimo em maiores alturas de plantas de A. mangium aos 40 (A40) e aos 60 (A60) dias após a germinação (Figura 3AB).

$*, * *$ e $* * *$ significativos a 5,10 e $0,1 \%$ de probabilidade, respectivamente, pelo teste $\mathrm{t}$.

${ }^{*},{ }^{* *} e^{* * *}$ significant at 5,10 e $0.1 \%$ probability, respectively, for the $t$ teste.
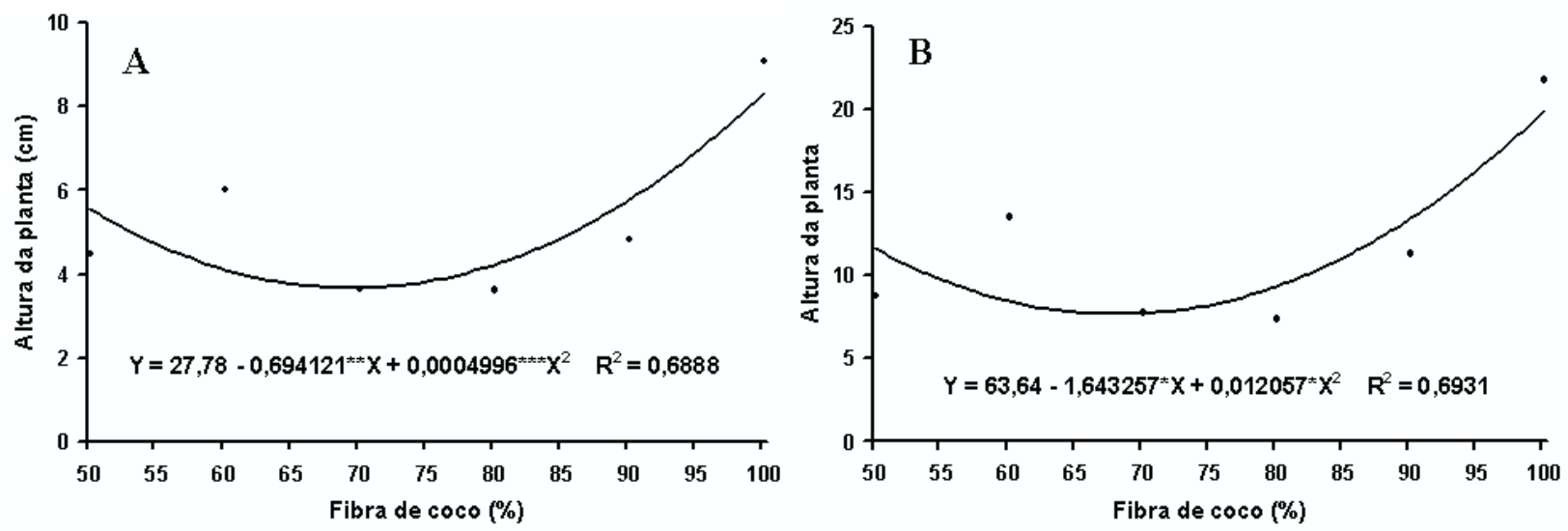

Figura 3 - Altura de plantas de A. mangium aos 40 (A) e 60 (B) dias após a germinação, em função da proporção de fibra de coco (FC) na "manta".

Figure 3 - Plant height of the A. mangium to the 40 (A) and the 60 (B) days after the germination in function of the proportion of fiber of coconut (FC) in the "blanket".

${ }^{\circ} \mathrm{e} *$ significativos a 10 e 5\% de probabilidade, respectivamente, pelo teste t.
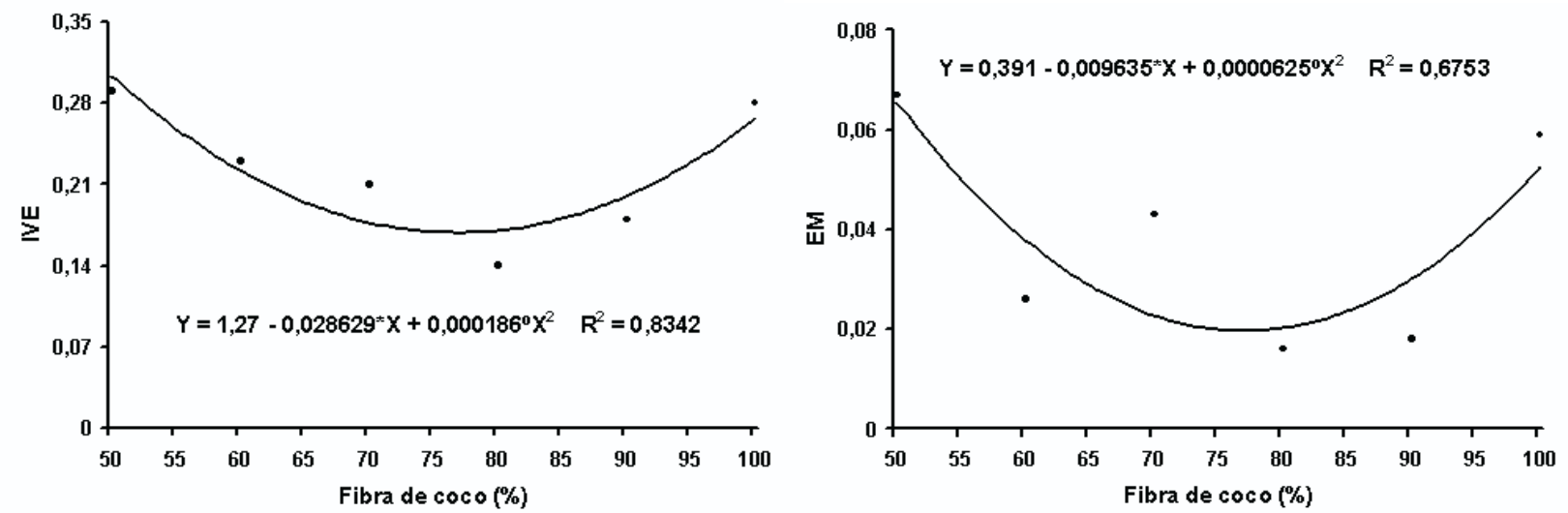

Figura 2 - Índice de Velocidade de Emergência (IVE) e percentagem de emergência (EM) de plantas de A. mangium em função da proporção de fibra de coco (FC) na "manta”. Para EM, as médias foram transformadas para arcosseno $(\mathrm{x} / 100)^{0,5}$.

Figure 2 - Index of Emergency Speed (IVE) the emergency percentage (EM) of plants de A. mangium in function of the proportion of fiber of coconut (FC) in the blanket. For EM the averages had been transformed for arc sine $(x / 100)^{0,5}$. 
$*$, ** e $\mathrm{e}^{* * *}$ significativos a 5, 10 e $0,1 \%$ de probabilidade, respectivamente, pelo teste $\mathrm{t}$.

$*$, ** $e^{* * *}$ significative at 5,10 e $0.1 \%$ probability, respectively, by $t$ test.
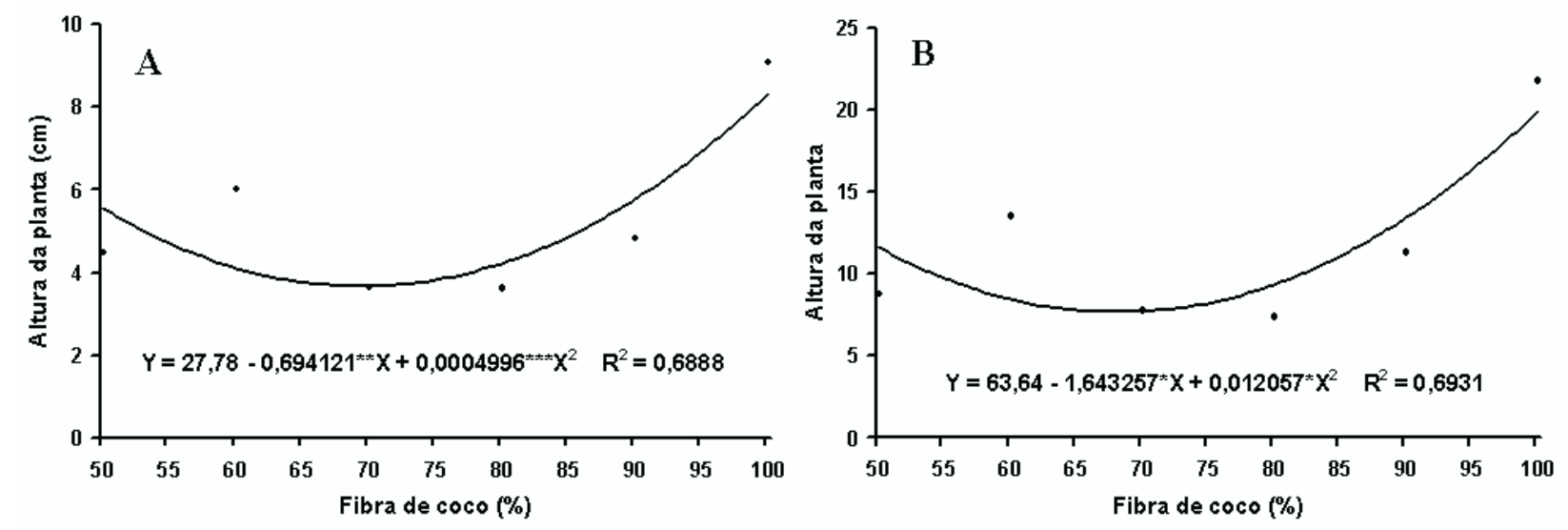

Figura 3 - Altura de plantas de A. mangium aos 40 (A) e 60 (B) dias após a germinação, em função da proporção de fibra de coco (FC) na "manta".

Figure 3 - Plant height of the A. mangium to the 40 (A) and the 60 (B) days after the germination in function of the proportion of fiber of coconut (FC) in the "blanket".

\section{DISCUSSÃO}

Os testes de germinação são realizados em laboratório sob condições ideais de temperatura, substrato, teores de umidade para o substrato e outros fatores que forneçam condições para que o lote de sementes possa expressar seu máximo potencial de germinação(FIGLIOLIA etal., 1993). Dessa forma, explica-se a superioridade dos valores quanto às características físicas e fisiológicas de sementes de $A$. mangium (Tabela 1 ).

Os fatores que certamente influenciaram na superioridade do tratamento-controle, em relação a IVE e EM, foram a presença de altas temperaturas e a baixa umidade do ar averiguada no período de realização do experimento, culminando com as condições de calor que devem ter atingido dentro da "manta”. A germinação de sementes é influenciada por fatores externos (luz, temperatura e disponibilidade de água, oxigênio e substrato) e internos (inibidores e promotores da germinação), que podem atuar por si ou em interação com os demais (KRAMER e KOZLOWSKI, 1972; NASSIF et al., 1998). De acordo com Carvalho e Nakagawa (1988), temperaturas inferiores ou superiores à ótima tendem a reduzir a velocidade do processo germinativo, expondo as plântulas por maior período a fatores adversos, o que pode levar à redução no total de germinação. Em trabalhos desenvolvidos com Acacia polyphylla, Araújo Neto et al. (2003) observaram aumento na porcentagem de germinação com o incremento da temperatura até
$25{ }^{\circ} \mathrm{C}$, tendendo a decrescer a partir daí. Soares e Rodrigues (2008) encontraram baixo potencial de emergência no campo com Mimosa bimucronata e Parapiptadenia rigida, por ocasião da estação da seca.

Quanto às variáveis de crescimento em altura das plantas aos 40 (A40) e 60 (A60) dias após a emergência, superiores às do tratamento-controle, resultado semelhante foi proposto por Braga et al. (2007), que obtiveram maior desenvolvimento de mudas de ipê-amarelo em solo orgânico não adubado mais serrapilheira, para um enriquecimento do sistema solo-serapilheira com espécies arbóreas aptas para recuperação de áreas degradadas. Entretanto, considerando-se os maiores ganhos em altura das plantas de A. mangium em “mantas” com proporções próximas a $100 \%$ de fibra de coco, isso implica as melhores condições propiciadas por esse substrato. Segundo Carrijo et al. (2002), as boas propriedades físicas da fibra de coco, a não reação com os nutrientes da adubação, a longa durabilidade sem alteração de suas características físicas, a possibilidade de esterilização, a abundância da matéria-prima que é renovável e o baixo custo para o produtor fazem desse resíduo substrato de excelente uso para a produção de mudas.

\section{CONCLUSÃO}

Diante dos resultados, conclui-se que:

1. O uso de lodo como substrato não influenciou no IVE e nem na EM, durante o desenvolvimento inicial de mudas de A. mangium no campo. 
2. Os tratamentos que apresentaram 50 e $100 \%$ de fibra de coco nas “mantas” proporcionaram melhor incremento inicial de mudas de A. mangium, em comparação com “mantas” nos demais tratamentos.

\section{REFERÊNCIAS}

ARAKI, D. F. Avaliação da semeadura a lanço de espécies florestais nativas para recuperação de áreas degradadas. 2005. 150p. Dissertação (Mestrado em Ecologia de Agroecossistemas) Universidade de São Paulo/ESALQ, Piracicaba, 2005.

ARAÚJO NETO, J. C.; AGUIAR, I. B.; FERREIRA, V. M. Efeito da temperatura e da luz na germinação de sementes de Acacia polyphylla DC. Revista Brasileira de Botânica, v.26, n.2, p.249-256, 2003.

BOEIRA, R. C. Lodo de esgoto como fertilizante em culturas anuais: acidez do solo. Jaguariúna: Embrapa Meio Ambiente, 2006. 3p.

BRAGA, A. J. T. et al . Enriquecimento do sistema solo-serapilheira com espécies arbóreas aptas para recuperação de áreas degradadas. Revista Árvore, v.31, n.6, p. 1145-1154, 2007.

BRASIL. Ministério da Agricultura e da Reforma Agrária. Regras para análise de sementes. Brasília: SNDA/DNDV/CLAV, 1992. 365p.

CAMPOS, F. S.; ALVES, M. C. Uso de lodo de esgoto na reestruturação de solo degradado. Revista Brasileira de Ciência do Solo, v.32, n.4, p. 1389-1397, 2008.

CARRIJO, O. A.; LIZ, R. S.; MAKISHIMA, N. Fibra da casca do coco verde como substrato agrícola. Horticultura Brasileira, v.20, n.4, p.533-535, 2002.

CARRIJO, O. A. et al. Produtividade do tomateiro em diferentes substratos e modelos de casas de vegetação. Horticultura

Brasileira, v.22, n.1, p. 5-9, 2004.

CARVALHO, N.M.; NAKAGAWA, J. Sementes: ciência, tecnologia e produção. 3·ed. Campinas: Fundação Cargill, 1988.
COLONNA, J. P. et al. Comparative effects of Glomus etunicatum and $\mathrm{P}$ fertilizer on foliar mineral composition of Acacia senegal seedlings inoculate with Rhizobium. Mycorrhiza, v.1, p.35-38, 1991.

DANIEL, O. et al. Aplicação de fósforo em mudas de Acacia mangium WILLD. Revista Árvore, v.21, n.2, p.163-168, 1997.

DUARTE, R. F. Crescimento inicial de Acacia mangium Willd em condicionador formado de fibra de coco e resíduo agregante com diferentes substratos. 2008. Monografia (Graduação em Engenharia Agronômica) - Universidade Federal de Minas Gerais, Montes Claros, 2008.

\section{EMPRESA BRASIELIRA DE PESQUISA}

AGROPECUÁRIA - EMBRAPA. Centro Nacional de Pesquisa de Agrobiologia (Seropédica, RJ). Revegetação de solos degradados. Seropédica, 1992. 11 p. (Comunicado Técnico, 10).

FARIA, J. M. R.; DAVIDE, A. C.; BOTELHO, S. A. Comportamento de espécies florestais em área degradada, com duas adubações de plantio. Cerne, v.3, n.1, p. 1-20, 1997.

FERREIRA, R. A. et al. Semeadura direta com espécies arbóreas para recuperação de ecossistemas florestais. Cerne, v.13, n.3, p.271-279, 2007.

FIGLIOLIA, M. B.; OLIVEIRA, E. C.; PIÑARODRIGUES, F. C. M. Análises de sementes. In: AGUIAR, I. B.; PIÑA- RODRIGUES, F. C. M.; FIGLIOLIA, M. B. (Coords.) Sementes florestais tropicais. Brasília: ABRATES, 1993. p.137-174.

KITAMURA, A. E. et al. Recuperação de um solo degradado com a aplicação de adubos verdes e lodo de esgoto. Revista Brasileira Ciência do Solo, v.32, n. 1, p. 405-416, 2008.

KRAMER, P. J.; KOZLOWSKI, T. Fisiologia das árvores. Lisboa: Fundação Calouste Gulbenkian, 1972. 745p.

MACEDO, A. C.; KAGEYAMA, P. Y.; COSTA, L. G. S. Revegetação: matas ciliares e de proteção ambiental. São Paulo: Fundação Florestal, p.24, 1993.

Revista Árvore, Viçosa-MG, v.35, n.1, p.69-76, 2011 
MAGUIRE, J. D. Speed of germination: aid in selection and evaluation for seedling emergence and vigor. Crop Science, v.1, p.176-177, 1962.

NASSIF, S. M. L.; VIEIRA, I. G.; FERNANDES, G. D. (LARGEA/). Fatores externos (ambientais) que influenciam na germinação de sementes.

Piracicaba: IPEF/LCF/ESALQ/USP, Informativo

Sementes IPEF, Abr -1998. Disponível em: http://www.ipef.br/sementes/. Acesso em: 27 de dez. 2007.

NEVES, C. S. V. J. et al. Efeitos de substratos e recipientes utilizados na produção das mudas sobre a arquitetura do sistema radicular de acácia-negra. Revista Árvore, v. 29, n. 6, p. 897-905, 2005.

ROSA, M. F. et al. Caracterização do pó da casca de coco verde usado como substrato agrícola. Fortaleza: Embrapa Agroindústria Tropical, 2001.6p. (Comunicado Técnico, 54).

SANTOS, I. C.; CASALI, V. W. D.; MIRANDA, G. $\mathrm{V}$. Teores de metais pesados, $\mathrm{K}$ e $\mathrm{Na}$, no substrato, em função de doses de composto orgânico de lixo urbano e de cultivares de alface. Ciência Rural, v.29, n.3, p.415-421, 1999.
SILVA, F. P.; BORGES, R. C. G.; PIRES, I. E. Avaliação de procedências de Acacia mangium Willd, aos 63 meses de idade, no Vale do Rio Doce - MG. Revista Árvore, v.20, n.3, p.299-308, 1996.

SILVA, F. C. et al. Efeito de lodo de esgoto na fertilidade de um Argissolo Vermelho-Amarelo cultivado com cana-de-açúcar. Pesquisa Agropecuária Brasileira, v.36, n.5, p.831-840, 2001.

SMIDERLE, O. J.; JUNIOR, M. M.; SOUSA, R. C. P. Tratamentos pré-germinativos em sementes de acácia. Revista Brasileira de Sementes, v.27, n. 1, p. 78-85, 2005,

SOARES, P. G.; RODRIGUES, R. R.

Semeadura direta de leguminosas florestais: efeito da inoculação com rizóbio na emergência de plântulas e crescimento inicial no campo. Scientia Forestalis, v.36, n.78, p.115-121, 2008.

SOUZA, E. B. et al . Germinação de sementes de Adenanthera pavonina L. em função de diferentes temperaturas e substratos. Revista Árvore, v. 31, n. 3, p. 437-443, 2007. 